\title{
Retrospection of heatwave and heat index
}

\author{
Amit Awasthi ${ }^{1}\left[\right.$ Kirti Vishwakarma ${ }^{2} \cdot$ Kanhu Charan Pattnayak ${ }^{3}[$
}

Received: 10 June 2021 / Accepted: 29 October 2021 / Published online: 11 November 2021

(c) The Author(s) 2021

\begin{abstract}
The frequency and intensity of extreme events especially heat waves (HW) are growing all around the world which ultimately poses a serious threat to the health of individuals. To quantify the effects of extreme temperature, appropriate information, and the importance of HW and heat index (HI) are carefully discussed for different parts of the world. Varied definitions of the HW and HI formula proposed and used by different countries are carried out systematically continent-wise. Different studies highlighted the number of definitions of HW; however, mostly used Steadman's formulae, which was developed in the late 1970s, for the calculation of HI that uses surface air temperature and relative humidity as climatic fields. Since then, dramatic changes in climatic conditions have been observed as evident from the ERA5 datasets which need to be addressed; likewise, the definition of $\mathrm{HW}$, which is modified by the researchers as per the geographic conditions. It is evident from the ERA5 data that the temperature has increased by $1-2{ }^{\circ} \mathrm{C}$ as compared to the 1980 s. There is a threefold increase in the number of heatwave days over most of the continents in the last 40 years. This study will help the researcher community to understand the importance of HW and HI. Furthermore, it opens the scope to develop an equation based on the present scenario keeping in mind the basics of an index as considered by Steadman.
\end{abstract}

Keywords Climate change $\cdot$ ERA5 $\cdot$ Extreme events $\cdot$ Heat wave $\cdot$ Heat index

\begin{abstract}
Abbreviations
HW Heat wave

HI Heat index
\end{abstract}

\section{Introduction}

The occurrence and strength of extreme heat events are increasing all around the world which has direct and indirect impacts on the health of living beings and the ecological system. Extreme heat events are physical hazards that cause health issues in eerie (Kent et al. 2014). These events also

Amit Awasthi

awasthitiet@gmail.com

Kanhu Charan Pattnayak

kcpattnayak@gmail.com

1 Department of Applied Sciences, University of Petroleum \& Energy Studies, Dehradun 248007, Uttarakhand, India

2 Department of Aerospace Engineering, University of Petroleum \& Energy Studies, Dehradun, Uttarakhand, India

3 School of Earth and Environment, University of Leeds, Leeds, UK affect the earth's warming process. One of the main reasons for the warming of the earth is due to the increase in concentrations of greenhouse gases received from different anthropogenic sources that produce a higher level of pollutions (Fischer et al. 2004). Researchers believe that this scenario of increase in temperature (Pattnayak et al. 2017) will continue aggressively in the future as well if no necessary steps are taken to control the pollution level. Modernization and industrialization provide new technologies that improve the lives of human beings, but along with this, severe impacts are observed on the environment. These new technologies consume a lot of energy that later on leads to produce air pollution and a lot of heat in the atmosphere which triggers many respiratory diseases (Chen et al. 2021; Fischer et al. 2004; Luan et al. 2019). As a result, the average temperature is increasing day by day which increases the possibilities of severe heatwave events that later on are responsible for the mortality rate (Hu et al. 2019). Climate change is considered to be the foremost reason behind these extreme events happening aggressively all around the world (Frich et al. 2002; Pattnayak et al. 2019; Trájer et al. 2019). The health impacts of heatwaves typically start from heat cramps, heat exhaustion, dehydration, and heatstroke that later on may lead to death, if necessary, care is not taken. Hence, along 
with other natural and anthropogenic reasons (Abbasnejad et al. 2019; Agarwal et al. 2010, 2013, 2014; Awasthi et al. 2017; Panda et al. 2020), extreme heat events also play an important reason for the number of causalities throughout the world (Fischer et al. 2004; Wang and Yan 2021).

The impact of the heatwave (HW) is not limited to the health of human beings (Kotharkar and Ghosh 2021; Nitschke et al. 2011; Pascal et al. 2021; Zhang et al. 2017) but agriculture, ecosystems, and the national economy too are also significantly affected by it (Luan et al. 2019). Extreme events like HW, cold waves, drought, floods, cyclones, tornadoes, hurricanes, etc. initially gained attention in the developed countries but, soon due to its global impacts it is discussed and of keen interest worldwide. However, it must be noticed that the events such as floods and tornadoes are a matter of concern if their occurrence leads to loss of human life, but events such as heatwaves and cold waves have both direct and indirect long- and short-term impacts on the environment and human life.

Among all the months, these extreme heat events normally occur in mid-summer and less intense heat waves also occur in early autumn and during spring. In summers, the value of feel like the temperature is much higher than that of the actual temperature. The feel-like temperature is scientifically termed as the Heat Index (HI) which accounts for humidity along with the actual temperature (Montero et al. 2013). Humidity is the amount of moisture or water vapors present in the atmosphere which is expressed in the terms of Relative Humidity. It makes the hot temperature even more unbearable as the presence of humidity in the environment reduces the ability of the body to cool itself. Due to this, in most $\mathrm{HI}$ formulas, the contribution of both, air temperature and relative humidity is visible.

There is no globally accepted standard HW definition (discuss in detail in coming section), although it is commonly defined as limited successive days with high temperatures above a certain threshold based on community and physiology (Montero et al. 2013). To study and manage heat-related risks imposed on health, HW and $\mathrm{HI}$ are needed to be considered wisely. The extent of adverse effects of $\mathrm{HW}$ can be carefully studied if $\mathrm{HI}$ is known for a particular region that has a direct relation with HW. Hence, in the coming sections, the definition of $\mathrm{HW}$ and the concept of $\mathrm{HI}$ are studied to understand their basics. The aim of the assessment done in the present paper is to clarify the definition of HW and HI so that their understanding shall help to reproduce the same. The key purpose is to understand the methods used by different countries to develop the relation of HI for their country as characterized by the data accumulated from different sources. In this paper, efforts are made to systemize maximum information about the basics of HW and HI to build a foundation for its understanding and to open new perspectives for young researchers, environmentalists, and policymakers, etc. for further modification and its application to minimize the hazardous effects of HW. The following section deals with the descriptions of HW and HI. Section 3 deals with the datasets used and the methodology adopted for this study. The classification of HW and HI across the different regions of the world has been discussed in Sect. 4, while the discussion has been made in Sect. 5. Summary and concluding remarks are provided in Sect. 6.

\section{Descriptions of heat wave and heat index}

\subsection{Heat wave (HW)}

Extreme heat events are named like HW, heat advisory, excessive heat event, and hot spell, etc. are commonly referred to as temperatures that are either unusually high compared to characteristic local environments or extend to the level which may harm human health and infrastructure. HW is one of the slightest considered terms which have systematic significant risks to the world. HW is tough to characterize, and there is no specific meaning of an HW because similar meteorological situations can establish an HW in one place but not in another. Definition of HW is based on the three categories i.e., media, area-wise, and an all-inclusive one (Perkins and Alexander 2013). Due to the absence of a generic definition of HW, different countries are using different criteria for HW, which are observed from Table 1 (Tong et al. 2010). It demonstrates the diverse definitions used to characterize HW and distinctive criteria were taken to characterize its meaning in the diverse era. To characterize the heat waves from various nations, distinctive sources are taken. It is clearly understood from Table 1 that different nations used their definition in which reference temperature and duration varied as per the variation in their meteorological parameters.

Table 1 highlighted that there are several diverse definitions of HW which are adapted by the researchers based on their local climatic zones. These HW definitions are based on the duration of $\mathrm{HW}$, a threshold of temperature (e.g., a relative threshold or an absolute threshold), and temperature indicator e.g., daily average, minimum, and maximum temperature, etc. To support the above statement, a review done by the various authors on different continents will be highlighted in the later section with the only aim that is to understand the logic behind the adoption of a different definition of HW. Before that, first of all understand briefly about the HI.

\subsection{Heat index (HI)}

Along with temperature, relative humidity $(\mathrm{RH})$ plays a vital role to calculate the effects of extreme heat events, because 
Table 1 Definitions of heat wave used in literature (Tong et al. 2010)

\begin{tabular}{|c|c|c|}
\hline Definition & Region & Reference \\
\hline $\begin{array}{l}\text { If a minimum temperature not below } 26.7^{\circ} \mathrm{C} \text { is recorded for at least } 48 \text { con- } \\
\text { secutive hours, it is termed as heat wave }\end{array}$ & USA & (Robinson 2001) \\
\hline $\begin{array}{l}\text { If the daily maximum temperature exceeds } 35^{\circ} \mathrm{C} \text { for a period of } 3 \text { or more } \\
\text { consecutive days, it is termed as heat wave }\end{array}$ & Australia & (Hansen et al. 2008) \\
\hline $\begin{array}{l}\text { If the daily maximum temperature exceeds } 37^{\circ} \mathrm{C} \text { for a continuous period of } \\
2 \text { days, it is termed as heat wave }\end{array}$ & Global definition & Global Climate Report 2013(NOAA 2013) \\
\hline $\begin{array}{l}\text { Periods of at least } 3 \text { consecutive days when the maximum and the minimum } \\
\text { temperature, averaged, were simultaneously greater than their respective } 95^{\text {th }} \\
\text { percentile }\end{array}$ & France & (Rey et al. 2007) \\
\hline $\begin{array}{l}\text { For Global analysis except for larger areas like Africa and } \mathrm{S} \text {. America, if } \\
\text { the daily maximum temperature exceeds average temperature by } 5^{\circ} \mathrm{C} \text {, it is } \\
\text { termed as heat wave }\end{array}$ & $\begin{array}{l}\text { Globe except for } \\
\text { larger areas like } \\
\text { Africa and S. } \\
\text { America }\end{array}$ & (Frich et al. 2002) \\
\hline $\begin{array}{l}\text { For Europe, China, Russia, Eastern US, Chicago, if the daily maximum tem- } \\
\text { perature exceeds } 35^{\circ} \mathrm{C} \text { for at least } 2 \text { consecutive days, it is termed as heat } \\
\text { wave }\end{array}$ & $\begin{array}{l}\text { Europe, China, } \\
\text { Russia, Eastern } \\
\text { USA, Chicago }\end{array}$ & (Russo et al. 2017) \\
\hline $\begin{array}{l}\text { If the daily maximum temperature exceeds } 33.59{ }^{\circ} \mathrm{C} \text { for a continuous period of } \\
3 \text { days, it is termed as heat wave }\end{array}$ & Global definition & Global Climate Report 2015(NOAA 2016) \\
\hline $\begin{array}{l}\text { If the daily maximum temperature exceeds } 32.65^{\circ} \mathrm{C} \text { for a continuous period of } \\
3 \text { days, it is termed as heat wave }\end{array}$ & Global definition & Global Climate Report 2015(NOAA 2016) \\
\hline $\begin{array}{l}\text { Heatwaves were defined when daily maximum temperature values exceeded the } \\
\text { 90th percentile for at least } 3 \text { consecutive days }\end{array}$ & South Africa & (Lyon 2009) \\
\hline
\end{tabular}

it is not only the heat that poses an effect. It is also the RH that is used to determine how hot and humid it feels based on the combined effect of temperature and humidity. This combined effect is represented by the mathematical term called HI. Basically, HI measures how hot it feels actually when $\mathrm{RH}$ is considered with air temperature. $\mathrm{HI}$ is one of the methods which can be used to access the potential risk of an extreme event like HW. As the environmental conditions of all the countries in the world are not the same, different countries use different definitions to define the HW based on different metrological parameters range. Additionally, they calculated HI for their area using the Steadman Scheme. This is developed by using multiple regressions such as the Poisson Regression analysis technique on the meteorological data (Steadman 1979). This formula which is called HI is applicable over a certain threshold value of temperature depending on the maximum temperature and relative humidity and is shown in the equation below.

$$
\begin{gathered}
H I=-42.379+2.04901523 x T+10.1433127 x \\
R H-0.22475541 x T x R H-6.83783 x 10^{-2} x T^{2} \\
-5.481717 x 10^{-2} x R H^{2}+1.2287410^{-3} x T^{2} x R H \\
+8.528210^{-4} x T x R H^{2}-1.99 x 10^{-6} x T^{2} x R H^{2}
\end{gathered}
$$

where HI: Heat Index in ${ }^{\circ} \mathrm{F}$; RH: Relative Humidity in \%, $\mathrm{T}$ : Ambient Dry Bulb Temperature in ${ }^{\circ} \mathrm{F}$.

This formula is used by different researchers around different parts of the world to access the effects of HW on human beings. Based on HI, the heat index calculator
Table 2 Risk conditions experienced by individuals at a different range of heat indices

\begin{tabular}{ll}
\hline Heat index & Risk conditions by prolonged physical activity \\
\hline$<27{ }^{\circ} \mathrm{C}$ & Comfortable \\
$27-32{ }^{\circ} \mathrm{C}$ & Fatigue \\
$32-41{ }^{\circ} \mathrm{C}$ & Muscle cramps, sunstroke, heat cramps \\
$41-54{ }^{\circ} \mathrm{C}$ & Sunstroke, muscle cramps, exhaustion, heatstroke \\
$<54{ }^{\circ} \mathrm{C}$ & Sunstroke/heatstroke \\
\hline
\end{tabular}

or heat index chart provide different zones like caution, extreme caution, danger, and the extreme danger zone (Table 2).

By understanding these zones, necessary steps will be taken to minimize the effects of HW. It is interesting to find in the coming section that most countries use Eq. (1) for the measurement of $\mathrm{HI}$ with their own modified HW definitions. HW studies and reviews done by authors in most of the continents of the world like the USA, Africa, Europe, Australia, and Asian countries like India, Taiwan, and Bangladesh, are discussed in the coming section of this paper. Studies are selected in such a way that it gives the basic idea of HW and HI and covers almost all the continents. Definitions used to characterize the HW of these countries are summarized in Table 3 which are elaborated in the next sections, along with several other countries to understand the reason behind the difference in the definitions. 
Table 3 Definitions of heat wave discussed in the present paper

\begin{tabular}{|c|c|c|c|c|}
\hline Definition & Day & & Region & Reference \\
\hline $\begin{array}{l}\text { "A time interval of at least } 2 \text { days with maximum apparent temperature exceed- } \\
\text { ing the } 90^{\text {th }} \text { percentile of the monthly distribution." }\end{array}$ & 2 & Europe & & (D’Ippoliti et al. 2010) \\
\hline $\begin{array}{l}\text { "If the daily maximum temperature exceeds } 30^{\circ} \mathrm{C} \text { for a continuous period of } \\
3 \text { days, it is termed as heat wave in Hilly regions of India." }\end{array}$ & 3 & Hilly Regions, India & & (Deoras 2016) \\
\hline $\begin{array}{l}\text { "If the daily maximum temperature exceeds } 40^{\circ} \mathrm{C} \text { for a continuous period of } \\
3 \text { days, it is termed as heat wave in plain regions of India." }\end{array}$ & 3 & Plain Regions, India & & (Deoras 2016) \\
\hline $\begin{array}{l}\text { "If the daily max temperature exceeds } 37^{\circ} \mathrm{C} \text { for a continuous period of } 3 \text { days, it } \\
\text { termed as heat wave in coastal regions of India." }\end{array}$ & 3 & Coastal Regions, India & & (Deoras 2016) \\
\hline $\begin{array}{l}\text { "Period } \geq 3 \text { consecutive days with maximum temperature above the } 90 \text { th percen- } \\
\text { tile of daily maxima temperature, centered on a 31-day window." }\end{array}$ & 3 & Africa & & (Ceccherini et al. 2017) \\
\hline $\begin{array}{l}\text { "The top 5\% ( } \$ 32.65 \mathrm{uC}) \text { of daily maximum temperatures for a continuous } 5 \text { days } \\
\text { period." }\end{array}$ & 5 & Brisbrane, Australia & & (Tong et al. 2010) \\
\hline $\begin{array}{l}\text { "Absence of normal pre-monsoonal rainfall which is brought by aberrant strong } \\
\text { low-level westerly winds and weak southerlies for consecutive } 10 \text { days is } \\
\text { defined as heatwaves." }\end{array}$ & 10 & Bangladesh & & (Nissan et al. 2017) \\
\hline $\begin{array}{l}\text { "If the sweltering climate continues for } 16 \text { successive days, with temperatures } \\
\text { achieving } 36^{\circ} \mathrm{C} \text {, it is termed as heatwave." }\end{array}$ & 16 & Taiwan & & (Lin et al. 2013) \\
\hline
\end{tabular}

\section{Data and methodology}

Weather variables were used in this study as direct input to the HI equation. Data were obtained from a public dataset, ERA5 (Hersbach et al. 2020), generated and hosted by the European Centre for Medium-range Weather Forecasts (ECMWF). ERA5 is a reanalysis dataset (hereafter called proxy observed) that provides weather variables homogeneously distributed at the global scale $(30-\mathrm{km}$ horizontal resolution), which are obtained from point-specific ground, ocean, atmosphere, and satellite observations through the application of a data assimilation system based on the ECMWF Integrated Forecasting System and a 4-dimensional variational analysis (4D-Var). In this study, the following surface variables were retrieved for the European domain as a proxy for meteorological observations: the daily mean temperature at $2 \mathrm{~m}$ and relative humidity. Both variables have a 3 -h time resolution. The study period has been chosen as 40 years starting from 1979 till 2018, to understand the mean behavior of these meteorological parameters and their trends over different parts of the globe. The time series over the specific regions have been extracted by taking the mask of those specific regions. This daily data series is used to prepare the mean annual cycle or the temporal variation of the climatic fields over different regions.

\section{Worldwide classification of heatwave and heat index}

HW and HI have been used differently in different parts of the world. The definition mainly differs because of the temperature and relative humidity of that region. Many studies suggest that the global temperature has been increased more rapidly in the last decade and therefore the $\mathrm{RH}$ has also changed significantly (Byrne and O'Gorman 2018; Cheng et al. 2018; Lau et al. 2021; Liu et al. 2018; Pattnayak et al. 2016; Sharma and Babel 2014; Tiwari et al. 2016). Relation between temperature and RH and their effect on health issues is studied by different authors (Awasthi et al. 2020; Mozumder et al. 2021; Sahu et al. 2021; Talbot et al. 2021). To examine, how the temperature and $\mathrm{RH}$ changes have affected the HI, the study period has been divided into two periods which are 1979 to 1988 (1980s) and 2009 to 2018 (2010s). Figure 1 depicts the mean air temperature at $2 \mathrm{~m}$ and Fig. 2 shows the RH for the two periods and changes in the 2010s with respect to the 1980s. It can be observed that the temperature increased (Fig. 1) over most of the globe except over a few parts of Antarctica (Doran et al. 2002; Oliva et al. 2017; Sancho et al. 2017) and the eastern part of the equatorial Pacific ocean (Kosaka and Xie 2013; Martínez-Garcia et al. 2010; Moum et al. 2013; Zhang et al. 2010). The rate of increase in temperature is more in the polar region than in the tropical and subtropical regions. In the northern pole, the temperature has increased by more than $3{ }^{\circ} \mathrm{C}$, while the temperature change is about $1-2{ }^{\circ} \mathrm{C}$ over the tropical region. The change in $\mathrm{RH}$ (Fig. 2c) is a more or less similar pattern to the temperature (Fig. 1c). In most of the regions, where the temperature has increased, the $\mathrm{RH}$ has also increased and vice versa. In the Antarctica region, the RH decreased and over the Arctic region, it is increased. Furthermore, the change in the climatic fields over the continents has been discussed in the following subsections. Few regions have been selected in each of the continents just to show how the climatic fields have changed and how it may affect HI. 
Fig. 1 Mean temperature at $2 \mathrm{~m}$ $\left({ }^{\circ} \mathrm{C}\right)$ from ERA5 for the period (a) 1979-1988, (b) 2009-2018, and (c) change between these two periods
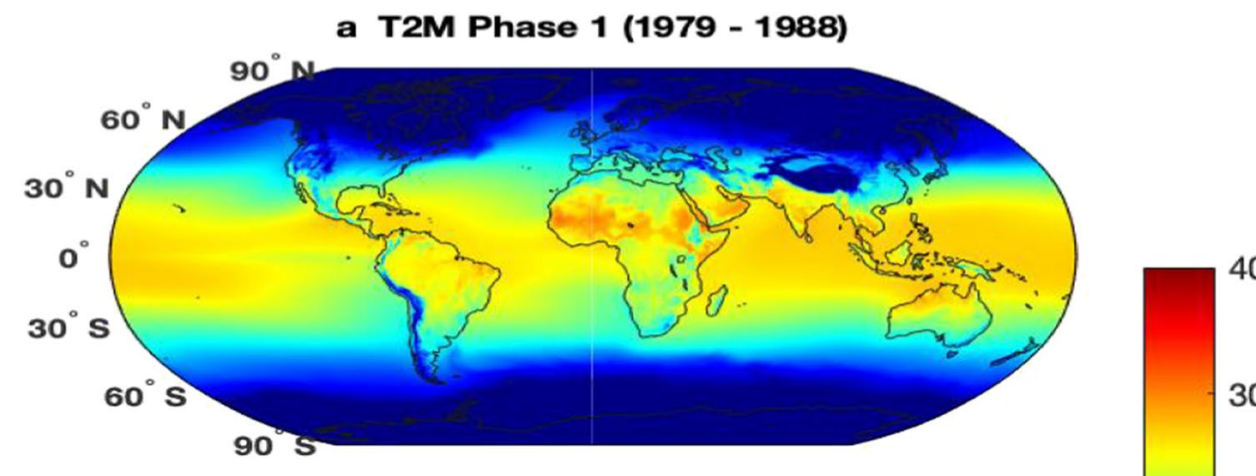

40

30

20

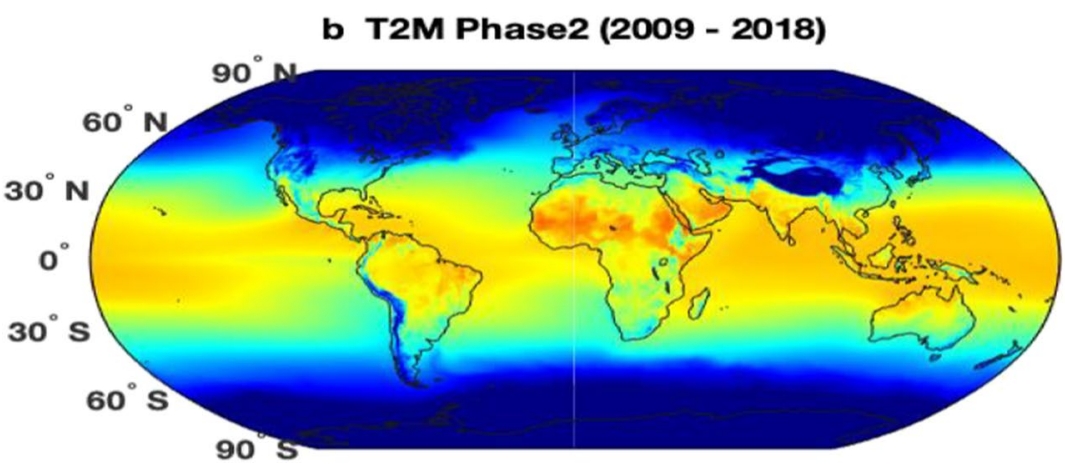

c Change (b - a)



\subsection{Asia}

Asia is one of the largest and populated continents of the world and is supposed that $60 \%$ of the total population of Earth is living here. Asia has extremely diverse climates range from arctic and subarctic in Siberia to tropical in southern India and Southeast Asia. Some of the countries from Asia are discussed in the incoming section, where it is understood that with the vast variation in temperature across Asia mostly used the same Eq. 1 for HI with a different definition of HW.

\subsubsection{China}

Ding et al. (2010) summarize the details of HW in China during 1961-2007 (Ding et al. 2010). Two definitions are quoted in this paper, one definition is based on absolute criteria when the daily maximum temperature is greater than $35^{\circ} \mathrm{C}$. Another definition is relative, i.e., if the daily maximum temperature is greater than the $90^{\text {th }}$ percentile threshold of the local daily temperature distribution of the data. The analysis shows that HW events sharply increased in northwestern China and eastern China. The frequency 
Fig. 2 Mean relative humidity (\%) from ERA5 for the period (a) 1979-1988, (b) 2009-2018, and (c) change between these two periods
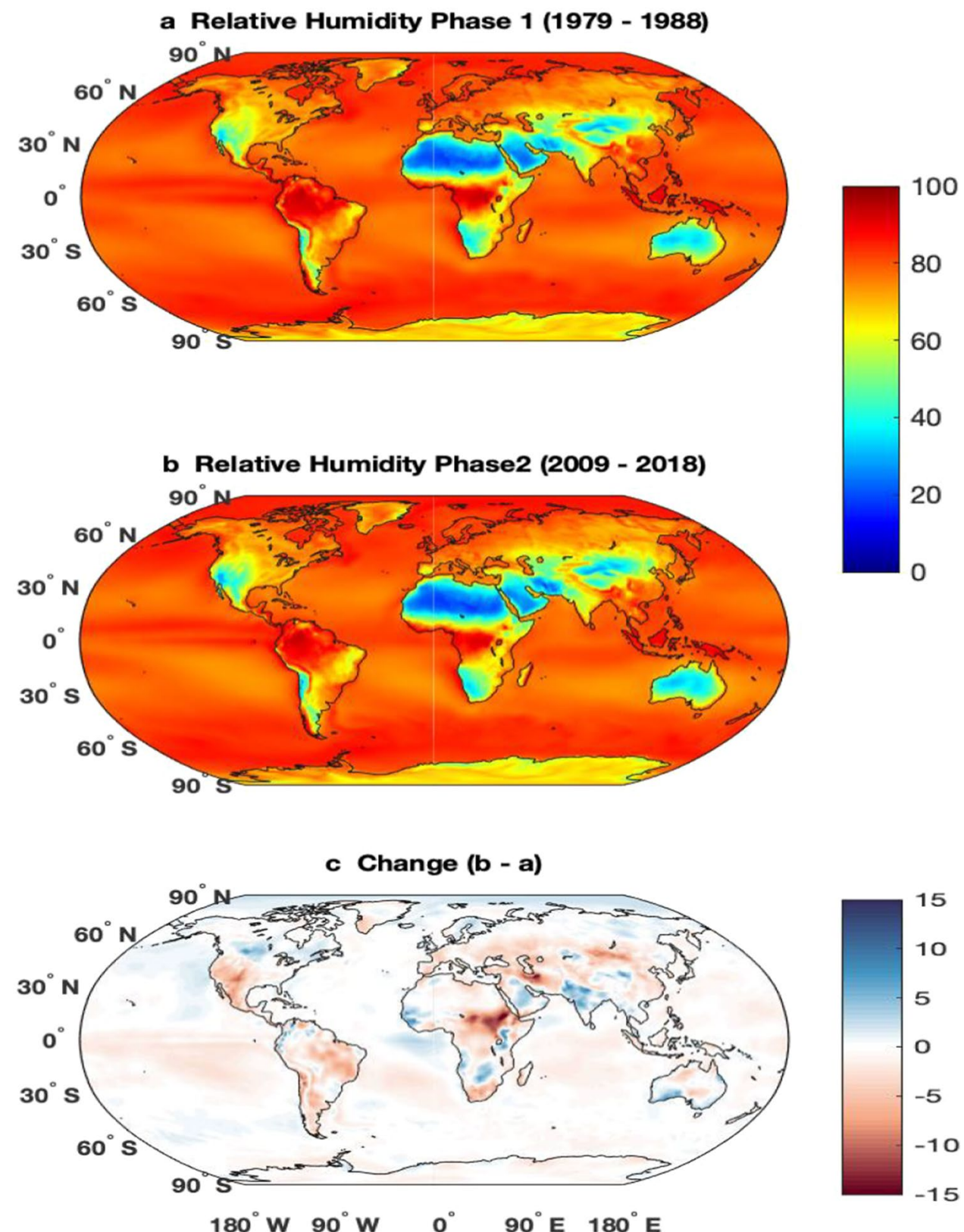

and intensity of HW both increase significantly in China. ERA5 temperature suggests that the average temperature has increased by about $2{ }^{\circ} \mathrm{C}$ (Fig. 3a) and the number of heatwave days has increased 3 times (Fig. 4) in the last 40 years.

\subsubsection{India}

India has a wide range of temperatures. States lying in the Eastern part of India have comparatively high temperature than western states but lower than that of northern states. Southern states like Tamil Nadu, Kerala have a humidified temperature throughout the year. According to National Survey, over 500 people die in a 3-day time period from May 20 to May 22, 2010. In May 2010, Ahmedabad that is lying in the western part of India faced HW where the temperature exceeded $46.8{ }^{\circ} \mathrm{C}$. A study was done to quantify the effect of HW on the mortality rate and to demonstrate the HW impact and calculate the correlation with mortality. Till 2009 , the daily average maximum temperature observed by the Ahmedabad was $40^{\circ} \mathrm{C}$, but an average temperature over $45^{\circ} \mathrm{C}$ was faced in May 2010 which resulted in a huge loss of lives (Azhar et al. 2014; Knowlton et al. 2014). In May 2015, Indian cities were struck by extreme warm waves, which regularly keep going during the dry season i.e. from March to July with the highest temperatures in April and May. It is documented that up to $3^{\text {rd }}$ June 2015,2500 individuals died at different locations in India (Rohini et al. 2016). According to Indian Meteorological Department (IMD), HW is 
Fig. 3 Interannual variation of temperature $\left({ }^{\circ} \mathrm{C}\right)$ and relative humidity (\%) over Asian countries for the period 1979 to 2018 from ERA5. The climate fields are averaged over China (top panel), India ( $2^{\text {nd }}$ panel from the top), Bangladesh ( $3^{\text {rd }}$ panel from the top) and Taiwan (bottom panel)

\section{T2M and Rhum over Asian Countries China}
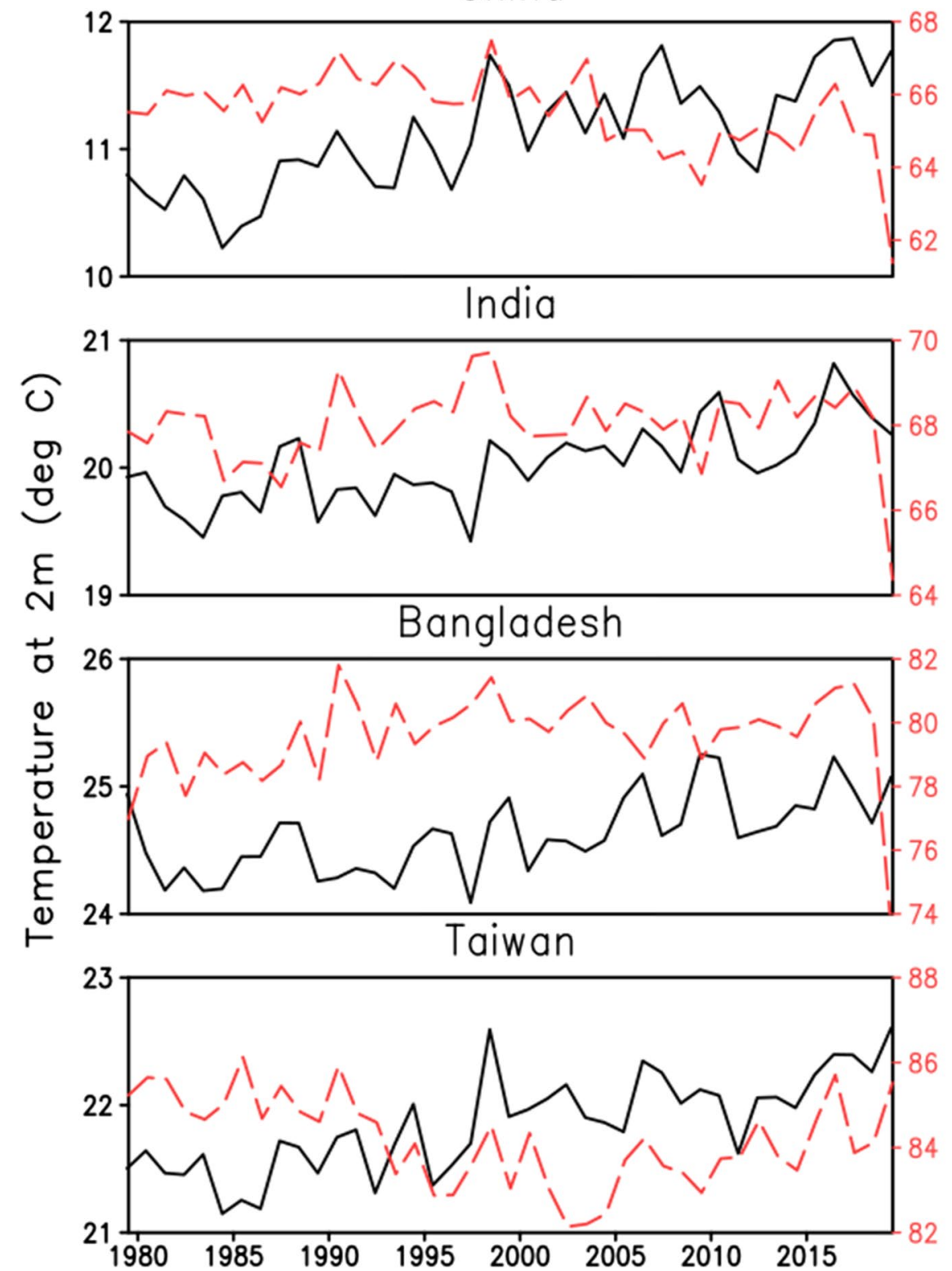

considered for plains, when the temperature exceeds $40{ }^{\circ} \mathrm{C}$, and for Hilly areas, when the temperature exceeds $30{ }^{\circ} \mathrm{C}$. If the extreme temperature stays at least $45^{\circ} \mathrm{C}$ regardless of the ordinary greatest temperature, it is termed as a heatwave. However, this is an average value that may differ for different regions. The majority of countries use the Steadman scheme to calculate the $\mathrm{HI}$ for their region. In the Himalaya regions of India, a different approach was used to calculate the HI i.e., Tree Rings method. Since there is a large variation of temperature in the Himalayan Region, so measurement of $\mathrm{HI}$ for the long term is a tedious process. Researchers chose generally two types of trees found in the Himalayan region i.e., Cedrusdeodara and Pinus roxburghii for these types of measurements. With the study of tree-ring width, Rainfall $(\mathrm{mm})$, Moisture Content, and Temperature are known. By using tree ring methods, Ram and Borgankar (2016) measured the different values of $\mathrm{HI}$ for different months in the Himalayan Region regarding the different values of average temperature which are calculated on the basis of rainfall, moisture content, humidity, and temperature. They have found that May and June are the most vulnerable times, as the $\mathrm{HI}$ and temperature have maximum values during this period. The change in the annual temperature is about $1{ }^{\circ} \mathrm{C}$ over India and there is no significant trend in relative humidity pattern (Fig. 3b). However, India has witnessed a threefold increase in the number of heatwave days (Fig. 4) in the 


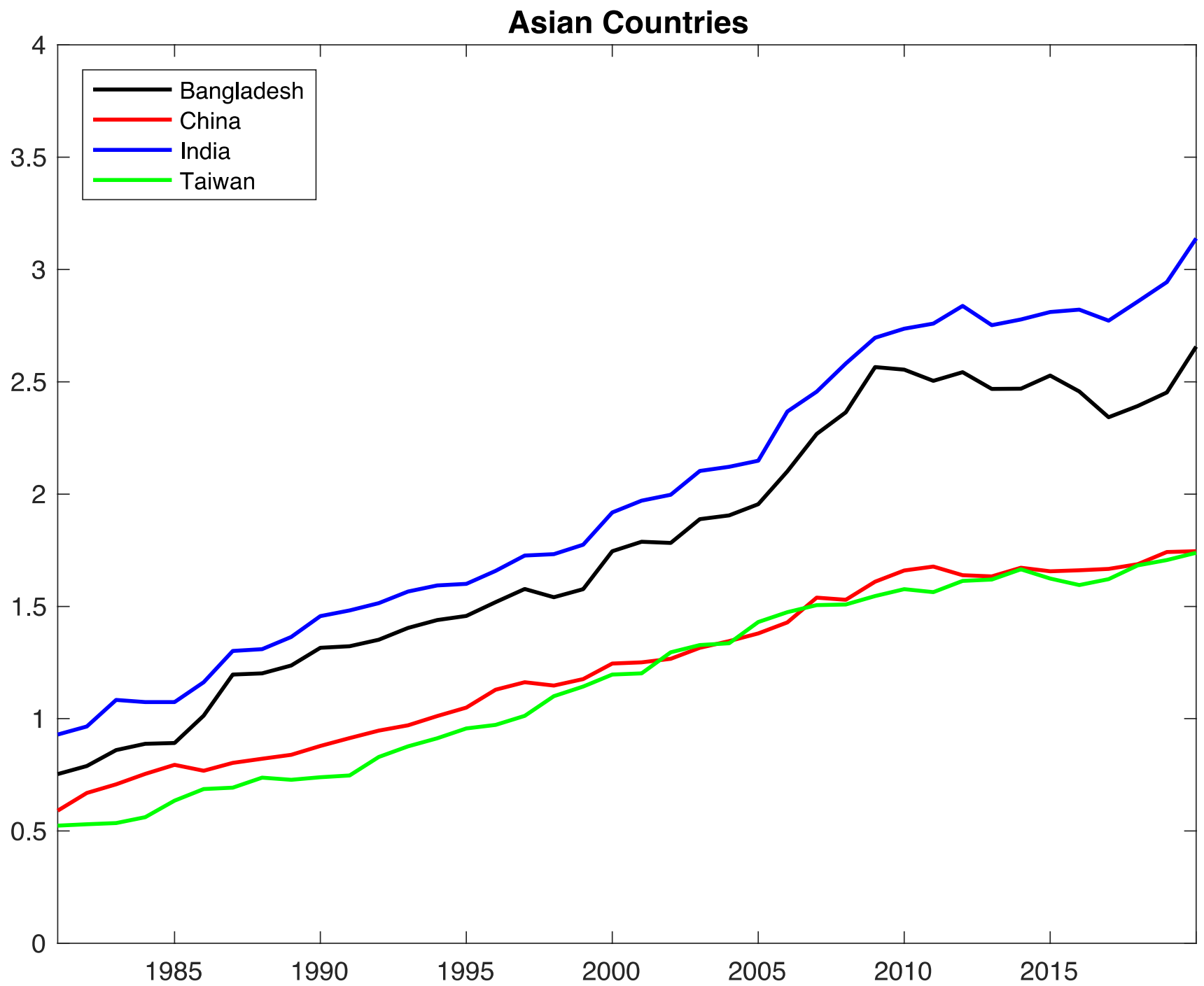

Fig. 4 Trend of heatwave days (no. of days per year) over the Asian countries for the period 1979 to 2018 from ERA5

last 40 years. Our findings over India agrees well with the study made by Mukherjee and Mishra (2018).

\subsubsection{Bangladesh}

Bangladesh faced one of the major heat waves between January 1994 and December 2002, as a total 13,720 lives were lost due to HW excluding external causes. In Bangladesh, absence of normal pre-monsoonal rainfall which is brought by aberrant strong low-level westerly winds and weak southerlies for consecutive 10 days is defined as heatwaves (Nissan et al. 2017). During the HW in 2008 for consecutive 8 days, at least 3800 lives were lost due to excess heat in which $2 / 3$ of lives were of people above 65 which indicates that the elderly is especially affected by the HW. Between 1982 and 2008, a total of 49,426 children under the age of 5 lost their lives due to HW with an average of 153 deaths per 1000 live births per month. This data had 4725 girls and 5459 boys that died at an age less than 5 months which resulted in 23 deaths/1000 births in a month (Babalola et al. 2018).

The mean HI value of Bangladesh $\left(42-50{ }^{\circ} \mathrm{C}\right)$ found matches to the average temperature of India during the summer season. The study of HI in Bangladesh was performed by dividing the country into four regions: (i) Central Area (CA), (ii) Northwest Area (NWA), (iii) Southwest Area (SWA), and (iv) East Area (EA) as shown in Table 3. This study by division of the country into various parts will help in understanding the procedure or methodology to develop HI for India. Using the real-time data of 20 stations out of 35 stations from Bangladesh Meteorological Department which included monthly dry bulb temperature and relative humidity for the period 1961-1990, HI was calculated. Such a formula in Eq. (1) is appropriate only when air temperature 
and humidity are higher than $26^{\circ} \mathrm{C}$ and $39 \%$, respectively. The HI value has an error of $\pm 1.3^{\circ} \mathrm{F}$, as it has been obtained by multiple regression analysis (Steadman 1979). It can be observed from Fig. $3 c$ that there is no significant change in both the climatic fields observed over Bangladesh. Our study shows that the number of HW (Fig. 4) has been increased by 2.5 times as compared to $1980 \mathrm{~s}$.

\subsubsection{Taiwan}

HW study was conducted in Taiwan, where extended mortality during warm waves has been attributed generally to cardiovascular conditions and cerebrovascular issues (Lin et al. 2013). Another study comprised of calculating the daily mean $\mathrm{HI}$ relationship with mortality by using Poisson regression analysis with generalized linear models (GLMs) in 6 major cities (Taipei, Keelung, Chiayi, Taichung, Kaohsiung, and Tainan) in Taiwan which lied between $26.4{ }^{\circ} \mathrm{C}$ $\left(79.5^{\circ} \mathrm{F}\right)$ and $28.6^{\circ} \mathrm{C}\left(83.4^{\circ} \mathrm{F}\right)$. The different parameters were studied, and average values were taken. The data was collected through Central Weather Bureau and US National Weather Service (Sung et al. 2013). The meteorological data of Taiwan was used to calculate the value of $\mathrm{HI}$ from 1994 to 2008. It contained the least daily mean values of Temperature and RH. When the meteorological data was substituted in Eq. (1), it was found that Keelung had the least value of HI i.e., $26.4 \pm 5.2^{\circ} \mathrm{C}$, and Kaohsiung had the greatest one, i.e., $28.6 \pm 4.9^{\circ} \mathrm{C}$ as they were dependent on the magnitude of Temperature and RH. Taiwan has experienced warming of about $1.5^{\circ} \mathrm{C}$ in the last 40 years, however, the increase rate is more during the recent decades (Fig. 3d). The trend of HW over the country roughly follows the trend of China (Fig. 4).

\subsection{Africa}

One of the hottest continents of the World is Africa in which the maximum average temperature of Earth is quoted at Dallol, Ethiopia. Many severe HW events were observed in different parts of Africa. One of the studies done by Lyon 2009 in Southern Africa, defines HW as a daily maximum temperature greater than 95 percentiles for at least 3 consecutive days. Ceccherini et al. (2017) reviewed the HW in Africa for a period from 1981 to 2015 , consider the HW as a "period $\geq 3$ consecutive days with maximum temperature above the 90th percentile of daily maxima temperature, centered on a 31-day window" (Ceccherini et al. 2017). Definition of HW is designed or modified after considering the metrological conditions of African countries. Figure 4 shows the interannual variation of temperature and relative humidity for the last 40 years. It suggests that the temperature has increased by $1{ }^{\circ} \mathrm{C}$ and the relative humidity has decreased by about $3 \%$ (Fig. 5). After 2000, both the climatic fields have been changed significantly. According to ERA5 data, the heatwaves have increased by 3.5 times over the continent (Fig. 9).

\section{North America}

The USA has been chosen to represent North America for this study, Smith et al. (2013) reviewed the HW in the USA for 40 years (Smith et al. 2013). In this paper, the authors' summarize data from the North American HW indices from 1979 to 2011. Sixteen definitions of HW indices were quoted, which differ in terms of temperature type i.e., minimum, maximum or average, threshold, durations, and type i.e. relative and absolute. etc. It is observed from this paper that $\mathrm{HW}$ is not unique meaning, but it is changed as per the geographical conditions, but focus and basic objective are the same in all the studies. There is a significant increasing trend in temperature (Fig. 6) and HW (Fig. 9) have been observed in the last 40 years.
Fig. 5 Interannual variation of temperature $\left({ }^{\circ} \mathrm{C}\right)$ and relative humidity (\%) over the African continent for the period 1979 to 2018 from ERA5. The climate fields are averaged over the whole African continent

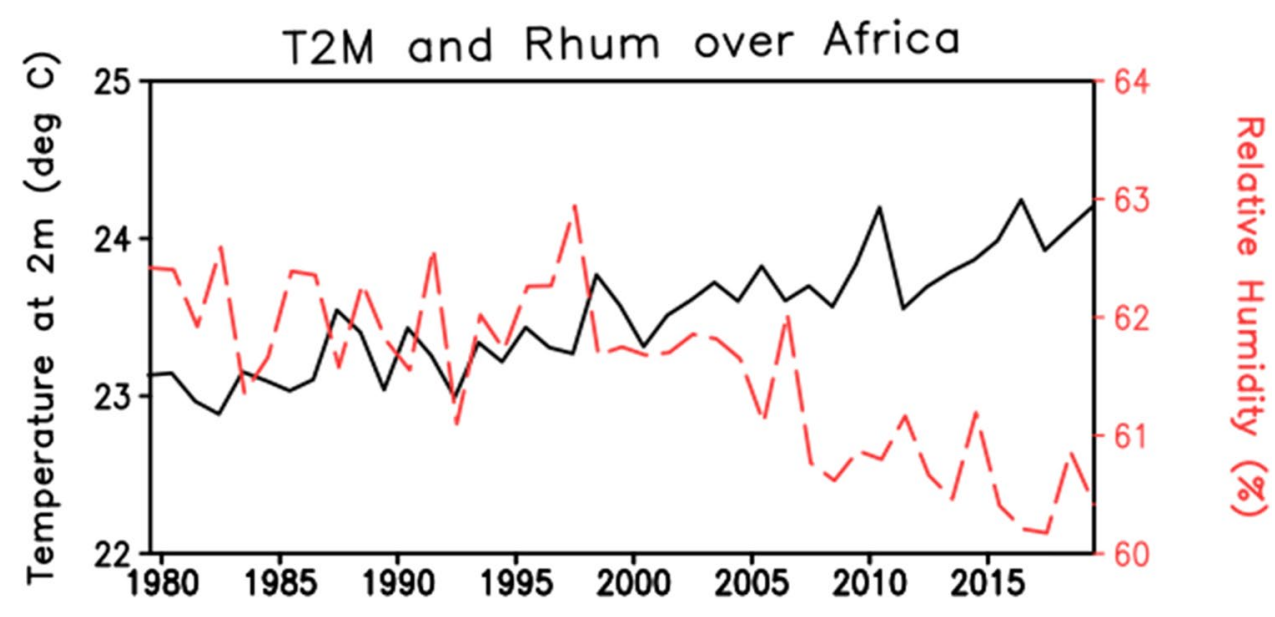


Fig. 6 Interannual variation of temperature $\left({ }^{\circ} \mathrm{C}\right)$ and relative humidity (\%) over the USA for the period 1979 to 2018 from ERA5. The climate fields are averaged over the USA

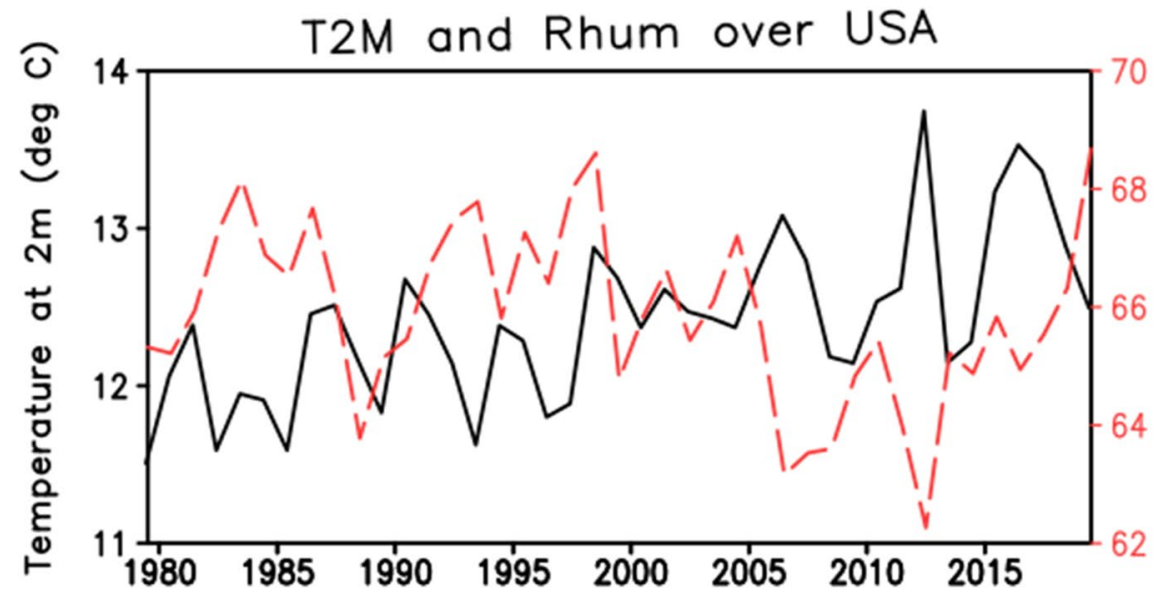

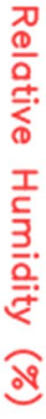

\subsection{Europe}

Europe was affected by two of the worst heat waves in summer 2003, the extreme maximum temperature of 35 to $40{ }^{\circ} \mathrm{C}$ was frequently recorded in July, which extended in August in most of the southern, and central countries from Germany to Turkey. It led to the hottest summer ever recorded in Europe since 1540 , with estimated excess mortality varying between 25,000 and 70,000 death in Western Europe (D'Ippoliti et al. 2010). A definition was given to HW according to which HW for Europe is defined as "A time interval of at least 2 days with maximum apparent temperature exceeding the $90^{\text {th }}$ percentile of the monthly distribution or a time interval of at least 2 days in which minimum temperature exceeds the $90^{\text {th }}$ percentile and maximum apparent temperature exceeds median monthly value". Concerned with this treacherous $\mathrm{HW}$, an attempt was made to develop the HI equation which could be used for further analysis in two regions of Europe, i.e., Marmara and Naples region.

\subsubsection{Marmara Region}

In Turkey, Marmara Region is the highest populated area. The HI here was distributed according to months accounted by the average values and not the extreme ones. For a period of 2007 and 2016, meteorological data like RH, wind speed, and temperature data were taken from 14 weather observation stations in Marmara Region, which were later utilized to calculate the HI (BURSALI and ŞEN 2017). For warm weather conditions (temperature greater than $21{ }^{\circ} \mathrm{C}$ ), $\mathrm{HI}$ is calculated by the same formula given in Eq. (1). Based on these index formulas, humans live comfortably below $21^{\circ} \mathrm{C}$, semi-comfortable up till $24{ }^{\circ} \mathrm{C}$, and very uncomfortably above the temperature of $27^{\circ} \mathrm{C}$. There is a steady increase in the temperature which is noticed in the ERA5 data (Fig. 1a). The temperature is increased by $1.5^{\circ} \mathrm{C}$ (Fig. 7) and $\mathrm{HW}$ by
3 times (Fig. 9) as compared to the 1980s. Conversely, the relative humidity has been decreased by about $4 \%$ (Fig. 7).

\subsubsection{Naples Region}

Two major severe heat waves of Europe in 2003 were taken into consideration while calculating $\mathrm{HI}$ of Naples. The temperature is affected by the hotter African anticyclone and milder Azores anticyclone during meridional circulation (Di Cristo et al. 2007). Again, Eq. (1) is used to calculate HI when the value of air temperature and humidity are higher than $26^{\circ} \mathrm{C}$ and $39 \%$, respectively, along with the wind speed to be $2.6 \mathrm{~m} / \mathrm{s}$. The rate of the change of temperature is moreover Marmara region (Fig. 7b). It may be noticed the $2{ }^{\circ} \mathrm{C}$ warmings have already occurred as compared to the 1980s.

Table 3 depicts the health impacts faced over the wide range of $\mathrm{HI}$ values in the Naples and Marmara region during the summer season which are grouped. This table is also called as heat index table which quantifies the effect of HW on individuals based on their risk. This includes the continuous or prolonged physical activity of individuals at their office or any workplace. These findings may help in understanding the adaptations that can be adopted by people living in that region for the betterment of their health since it affects them adversely.

\subsection{Australia}

Tong et al. (2010) studied the effect of extreme heat event on the health by measuring the hospital admissions in Brisbane, Australia which has sub-tropical climate (Tong et al. 2010). In this, the authors summarize the different definitions of HW used between 1996 and 2005 for Brisbane, Australia. Total ten definitions of HW were used in this study but for HI used is based on Steadman Eq. (1). Ten definitions of HW include the daily maximum 
Fig. 7 Interannual variation of temperature $\left({ }^{\circ} \mathrm{C}\right)$ and relative humidity $(\%)$ over the European region for the period 1979 to 2018 from ERA5. The climate fields are averaged over Naples region (top panel) and Marmara region (bottom panel)

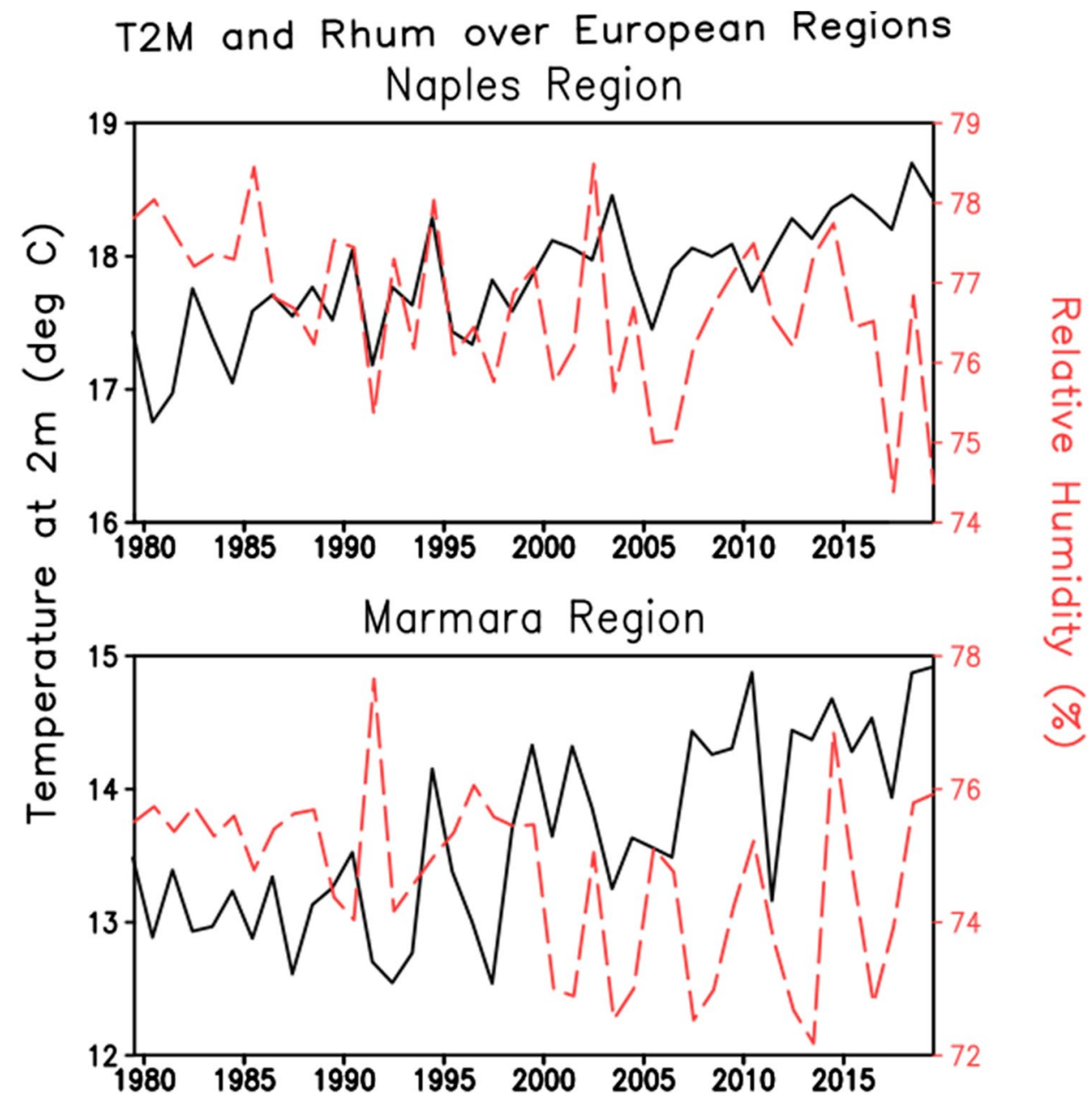

temperature greater than or equal to 1 to $5 \%$ for consecutively more than 2 to 5 days. This paper indicates that it is difficult to rely upon or use one definition of $\mathrm{HW}$ for different regions but rely on the Steadman Eq. (1). Increase in temperature (Fig. 8) and number of heatwaves days (Fig. 9) have been found.

\section{Discussion}

There are several diverse definitions of $\mathrm{HW}$ which are adapted by the researchers on the basis of their local climatic zones. These HW definitions are based on the duration of HW, exposure threshold of temperature (e.g., a relative
Fig. 8 Interannual variation of temperature $\left({ }^{\circ} \mathrm{C}\right)$ and relative humidity (\%) over the Australian continent for the period 1979 to 2018 from ERA5. The climate fields are averaged over Australia

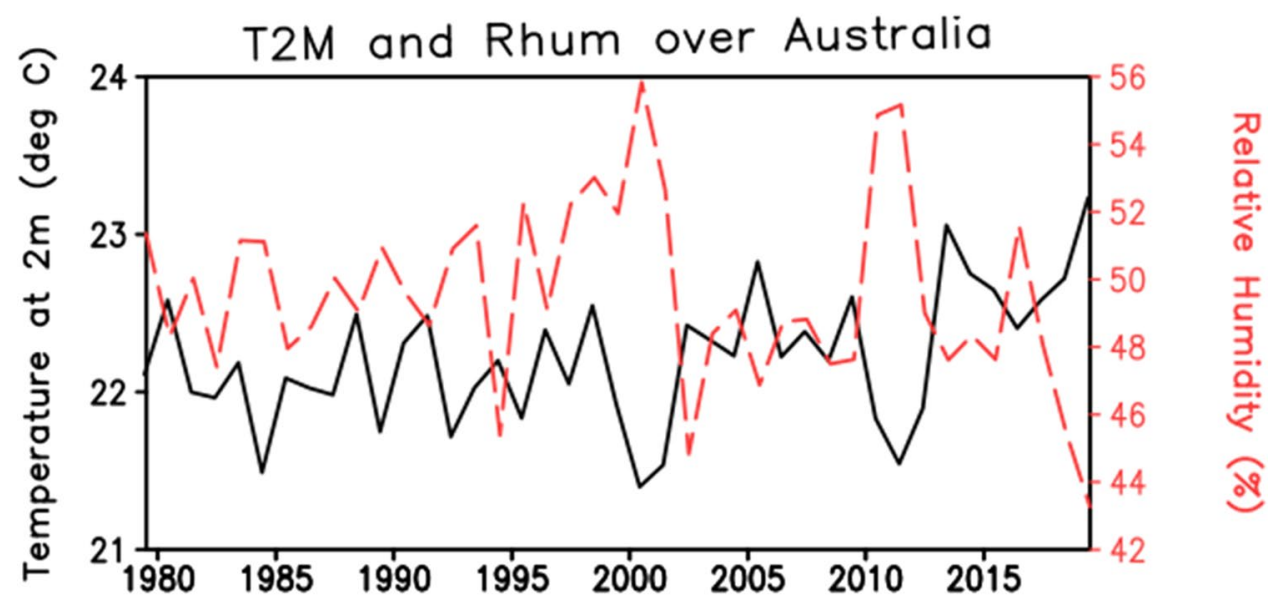




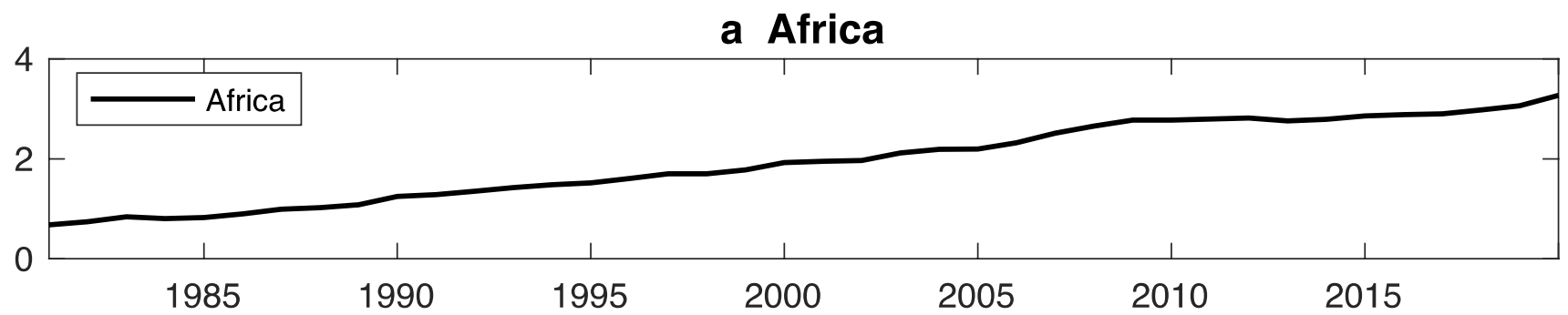

b Australia

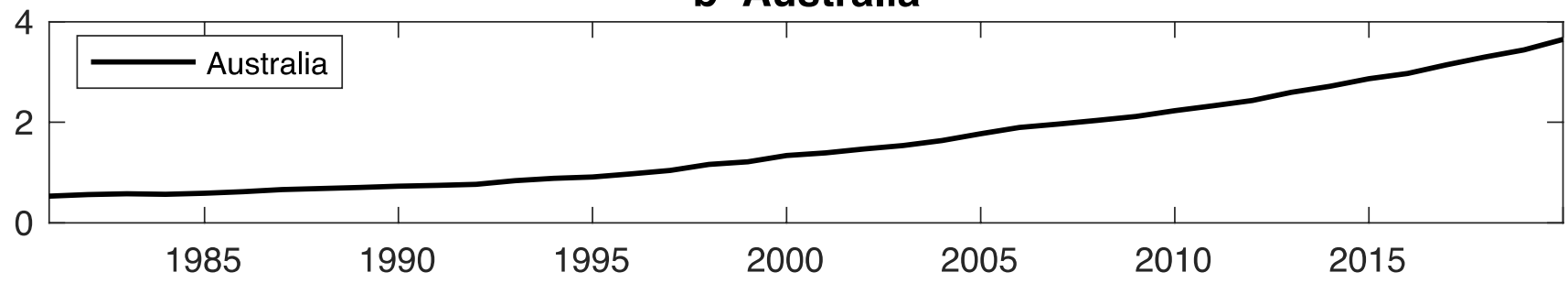

c European Regions

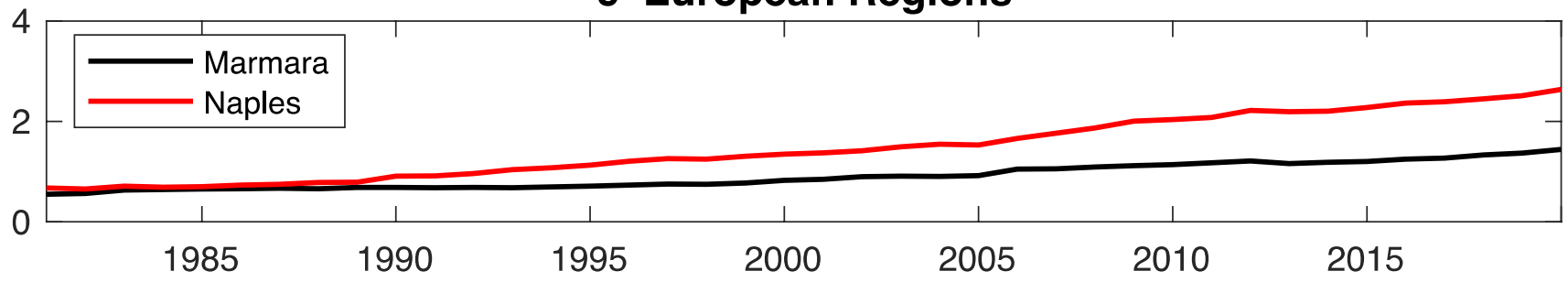

d North America

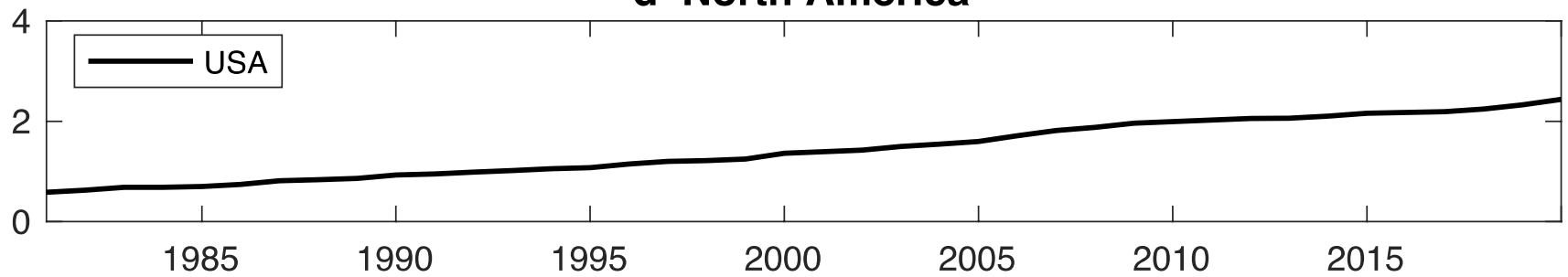

Fig. 9 Trend of heatwave days (no. of days per year) over a Africa, b Australia, c Europe, and d North America for the period 1979 to 2018 from ERA5

threshold or an absolute threshold), and temperature indicator (e.g., daily average, minimum and maximum temperature), etc. as shown in Fig. 10. Since HW is the consequence of climate change, air pollution, and/or Global Warming which is quantified mathematically by using $\mathrm{HI}$, therefore, the definition of HW depends upon different parameters and HI depends upon the relative humidity and temperature, which is used by Steadman in his equation by using the regression technique (Fig. 10). This Steadman equation (Eq. (1)) was derived in the 1980s and still, researchers used this equation to quantify the effect of HW.

The main purpose of this study focused on the definition of HW and HI for different countries which is characterized by the data accumulated from different sources. Overall, findings indicate that (i) at one region, HW may be termed for consecutive several days and at the other, even for 1 day. (ii) $\mathrm{HI}$ is consistently dependent on few parameters like air temperature and relative humidity, (iii) Steadman's equation is still used for quantification of the effect of $\mathrm{HW}$. This study helps to understand an outlook for developing/ modification of the existing $\mathrm{HI}$ equation for a country like India where the diverse temperature is observed by either developing an assortment of such equations for the entire country with special parameters included to result into the different equations for different regions in India due to the medley of environmental factors like temperature, relative humidity, etc. Steadman's equation was developed in the 1980s when the environmental conditions were entirely different in comparison to the present.

From Fig. 1, it is observed that temperature is high in the last decade 2009-2018 in comparison to the decade 1979-1988. The temperature rises to $3{ }^{\circ} \mathrm{C}$ during the period of 2009-2018 in comparison to the period of 1979-1988. In Fig. 1 and Figs. 3, 4, 5, 6, 7, a temperature 
Fig. 10 Parametric variation of heat wave and heat index

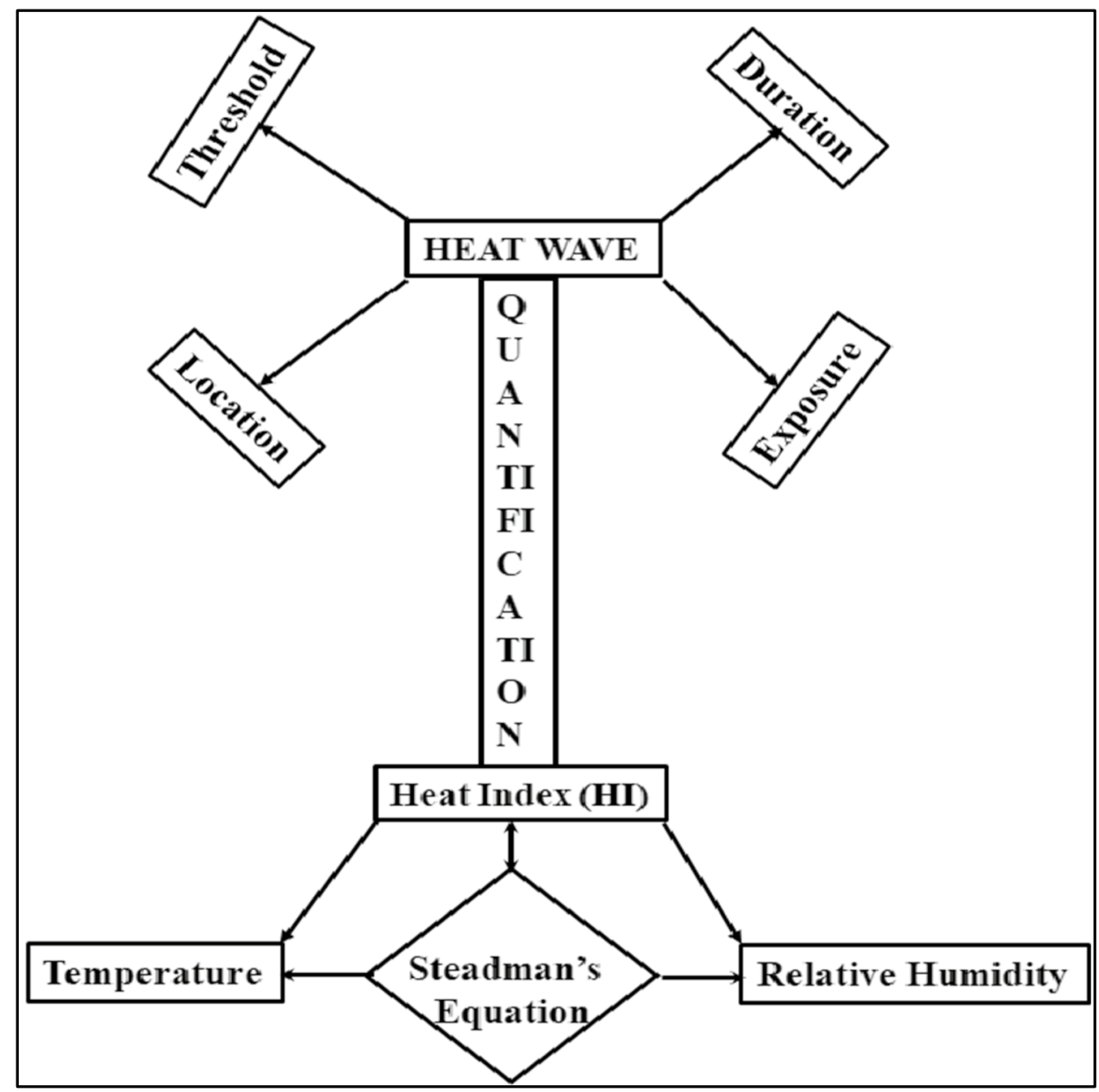

range of 20 to $30{ }^{\circ} \mathrm{C}$ is observed which seems quite low as per the temperature given in the generic definition of heatwave, i.e., nearly $35^{\circ} \mathrm{C}$ (Table 1 ). This is because the figures represent the annual average value that also includes winter season temperature thereby lowering the overall average annual temperature. Hence, if only the average value of the summer season is considered, especially peak intense heat days, then the value automatically reaches the heatwave range. So, the finding that there is an increase in temperature by 2-3 units will remain the same even after excluding the winter and monsoon season data. Therefore, necessary modifications in the existing equation are crucial. The alternative is to develop even-handed HI equations for different regions with similarities in their environmental condition to find the most suitable, comforting, and habitable zones. Many countries calculated HI which indicates the effect of the mortality rate of any region. The impact of HI is not limited to direct death but also other health issues like heat stroke, sunstroke, heat cramps, breathing difficulty, and decreased conscious level, and significantly lower diastolic blood pressure which makes the calculation and study of the Indian HI paramount. This paper reviewed different countries and their respective HW definition and relation between them.

The most discussed topic of present scenario in which relation of COVID1-9 cases with meteorological parameters are discussed (Awasthi et al. 2021; Singh and Vishal Mishra 2021; Tosepu et al. 2020) and many researchers proposed that COVID-19 cases increase with the increase in temperature during the summer (Bashir et al. 2020; Singh and Vishal Mishra 2021). During the summer, frequency and intensity of HW increases, who have already showed significant rise in premature death that poses high risk especially on the vulnerable groups due to Corona virus (Pijls et al. 2021). Hence it is necessary to modify the existing recommendations of heat-related illness with the consideration of infection due to different type of viruses (Reilly et al. 2021).

It is necessary and right time to identify the importance of HW and HI, as it helps in understanding the behavior of environmental conditions to live comfortably in a particular region and to reduce mortality and other diseases (Carmona et al. 2017; Shartova et al. 2018). Keeping this thing in mind; a review on the definition of $\mathrm{HW}$ and equations has been done because of studies done in different continents. 
The scrutiny of different studies in the present article has brought out the salient methods adopted by different countries to find $\mathrm{HI}$ relations and values in addition to heatwaves.

It is surmised from the survey that all the countries do not follow the same definition of HW as given by the World Meteorological Organization (WMO) i.e., "A period during which the daily maximum temperature exceeds for more than five consecutive days by the maximum normal temperature of $9^{\circ} \mathrm{F}\left(5^{\circ} \mathrm{C}\right)$ " but most of the countries have modified the definition as per their regional metrological data. Quantitatively, HI confirmed that the temperature experienced during the summer months with high humidity values is more in comparison to the other months. Generally, the different researchers used the Steadman equation for the calculation of HI. Accordingly, different countries developed or suggested their own precautionary steps to minimize the effects of HW caused by heatstroke and heat exhaustion like living in air-conditioned homes, etc. A warning system based on $\mathrm{HI}$ can be designed to study the effect of extreme events based on combined observation of high daytime temperatures, warm nighttime temperature, high humidity, and light winds for several successive days.

\section{Conclusion}

It is inferred from different studies that there is no exact definition of $\mathrm{HW}$, as these vary with respective regions. Different studies implied that it is difficult to develop a generic formula for HW for all the countries worldwide. It is evident from the ERA5 data that the temperature has increased by $1-2{ }^{\circ} \mathrm{C}$ and number of heatwaves has been increased three times and in most of the continents in the last 40 years. It is observed from HI calculation that both relative humidity and temperature are the main components for the equation and in most cases; Steadman's equation is used to quantify the effect of an extreme event like HW. Hence, to develop/ modify an equation of $\mathrm{HI}$ depends upon a diverse range of meteorological parameters like temperature, $\mathrm{RH}$, etc. Therefore, an enormous study of such parameters is required.

The development of a generic index for HW requires special correction parameters (or factors) or a value or a relation with respect to region. For this purpose, study on a mass level is required and countries need to be selected regionwise and based on meteorological variations so that every perspective of diverse variation in weather can be included. This study summarizes the basic ideas about the HW and HI so that this knowledge can provide a platform to develop or modify the existing definitions and formulas so that necessary steps can be taken to minimize the hazardous effect of extreme events like HW. As there are several definitions for $\mathrm{HW}$, but for HI, Steadman's equation is still used as a generic equation. There is a need to develop separate HI equations as per different geographical and climatic conditions. Therefore, the development/modification of the appropriate HI equation is needed for an hour and acts as future scope for this paper. The mathematical aspect of the HI equation can be handled by the mathematical expert with the joint effort of environmentalists for the development of HI.

Acknowledgements The authors are thankful to the University of Petroleum and Energy Studies, Dehradun, for providing research facilities. We acknowledge ECMWF for providing the climatic data. The ERA5 data is obtained from the European Centre for Medium-Range Weather Forecasts (https://cds.climate.copernicus.eu/live/queue).

Author contribution A.A. and K.C.P. conceived the study. A.A., K.V. and K.C.P. performed the analyses and wrote the initial draft of the manuscript. All authors contributed to the interpretation of the results, discussion of the associated mechanisms, and refinement of the paper.

Data and code availability All data used in this study are freely available and can obtained directly from the source: ERA5 data (https://cds. climate.copernicus.eu/live/queue). Alternatively, the data and codes can be made available on request to the authors.

\section{Declarations}

Ethics approval and consent to participate Not applicable

Consent for publication I consent to the publication of the article entitled "Retrospection of heatwave and heat index: A case study using ERA5 dataset." by A. Awasthi, K. Vishwakarma and K. C. Pattnayak in the journal Theoretical and Applied Climatology.

Conflict of interest The authors declare no competing interests.

Open Access This article is licensed under a Creative Commons Attribution 4.0 International License, which permits use, sharing, adaptation, distribution and reproduction in any medium or format, as long as you give appropriate credit to the original author(s) and the source, provide a link to the Creative Commons licence, and indicate if changes were made. The images or other third party material in this article are included in the article's Creative Commons licence, unless indicated otherwise in a credit line to the material. If material is not included in the article's Creative Commons licence and your intended use is not permitted by statutory regulation or exceeds the permitted use, you will need to obtain permission directly from the copyright holder. To view a copy of this licence, visit http://creativecommons.org/licenses/by/4.0/.

\section{References}

Abbasnejad B, Keshavarzi B, Mohammadi Z, Moore F, Abbasnejad A (2019) Characteristics, Distribution, Source Apportionment, and Potential Health Risk Assessment of Polycyclic Aromatic Hydrocarbons in Urban Street Dust of Kerman Metropolis, Iran. Int J Environ Health Res 29(6):668-685

Agarwal R, Awasthi A, Mittal S, Singh N, Gupta PK (2010) Effects of Air Pollution on Respiratory Parameters during the WheatResidue Burning in Patiala. J Med Eng Technol 34(1):23-28

Agarwal R, Awasthi A, Singh N, Mittal SK, Gupta PK (2013) Epidemiological Study on Healthy Subjects Affected by Agriculture 
Crop-Residue Burning Episodes and Its Relation with Their Pulmonary Function Tests. Int J Environ Health Res 23(4):281-295

Agarwal R, Awasthi A, Mital SK, Singh N, Gupta PK (2014) Statistical Model to Study the Effect of Agriculture Crop Residue Burning on Healthy Subjects. Mapan 29:57-65

Awasthi A, Hothi N, Kaur P, Singh N, Chakraborty M, Bansal S (2017) Elucidative Analysis and Sequencing of Two Respiratory Health Monitoring Methods to Study the Impact of Varying Atmospheric Composition on Human Health. Atmos Environ 171(May):32-37

Awasthi, Amit, Aditi Sharma, Prabhjot Kaur, Balakrishnaiah Gugamsetty, and Akshay Kumar (2020) "Statistical Interpretation of Environmental Influencing Parameters on COVID-19 during the Lockdown in Delhi, India." Environ Dev Sustain (0123456789).

Awasthi A, Sharma A, Kaur P, Gugamsetty B, Kumar A (2021) Statistical interpretation of environmental influencing parameters on COVID-19 during the lockdown in Delhi, India. Environ Dev Sustain 23:8147-8160

Azhar GS, Mavalankar D, Nori-Sarma A, Rajiva A, Dutta P, Jaiswal A, Sheffield P, Knowlton K, Hess JJ (2014) Heat-Related Mortality in India: Excess All-Cause Mortality Associated with the 2010 Ahmedabad Heat Wave. PLoS ONE 9(3):1-8

Babalola O, Razzaque A, Bishai D (2018) Temperature Extremes and Infant Mortality in Bangladesh: Hotter Months, Lower Mortality. PLoS ONE 13(1):1-9

Bashir MF, Ma B, Bilal K, \& Bashir B, M. A., Tan D and Bashir M (2020) "Correlation between climate indicators and COVID-19 pandemic in New York, USA." Sci Total Environ 728: 138835.

Bursali, Canan, and Orhan Şen (2017) "The Analysis of the Heat Index and Wind Chill in Marmara Region.” Pp. 71-78 in International 8th Atmospheric Sciences Symposium, Turkey.

Byrne MP, O'Gorman PA (2018) Trends in Continental Temperature and Humidity Directly Linked to Ocean Warming. Proc Natl Acad Sci USA 115(19):4863-4868

Carmona R, Linares C, Ortiz C, Mirón IJ, Luna MY, Díaz J (2017) Spatial Variability in Threshold Temperatures of Heat Wave Mortality: Impact Assessment on Prevention Plans. Int J Environ Health Res 27(6):463-475

Ceccherini G, Russo S, Ameztoy I, Marchese AF, Carmona-Moreno C (2017) Heat Waves in Africa 1981-2015, Observations and Reanalysis. Nat Hazard 17(1):115-125

Chen B, Xie M, Feng Q, Li Z, Chu L and Liu Q (2021) "Heat risk of residents in different types of communities from urban heatexposed areas." Sci Total Environ 768: 145052.

Cheng Q, Bai L, Zhang Y, Zhang H, Wang S, Xie M, Zhao D, Hong Su (2018) Ambient Temperature, Humidity and Hand, Foot, and Mouth Disease: A Systematic Review and Meta-Analysis. Sci Total Environ 625:828-836

Di Cristo R, Mazzarella A, Viola R (2007) An Analysis of Heat Index over Naples (Southern Italy) in the Context of European Heat Wave of 2003. Nat Hazards 40(2):373-379

D’Ippoliti D, Michelozzi P, Marino C,Francesca De'Donato, Bettina Menne, Klea Katsouyanni, Ursula Kirchmayer, Antonis Analitis, Mercedes Medina-Ramón, Anna Paldy, Richard Atkinson, Sari Kovats, Luigi Bisanti, Alexandra Schneider, Agnès Lefranc, Carmen Iñiguez, and Carlo A. Perucci. (2010) The Impact of Heat Waves on Mortality in 9 European Cities: Results from the EuroHEAT Project Environ Health: A Glob Access Sci Source 9(1):1-9

Deoras, Akshay (2016) "High Temperatures and More Heat Waves This Week." DownToEarth. Retrieved (https://www.downtoearth. org.in/blog/science-technology/high-temperatures-and-moreheatwaves-this-week-53616).

Ding T, Qian W, Yanb Z (2010) Changes in Hot Days and Heat Waves in China during 1961-2007. Int J Climatol 30(10):1452-1462

Doran PT, Priscu JC, Berry Lyons W, Walsh JE, Fountain AG, McKnight DM, Moorhead DL, Virginia RA, Wall DH, Clow
GD, Fritsen CH, McKay CP, Parsons AN (2002) Antarctic Climate Cooling and Terrestrial Ecosystem Response. Nature 415(6871):517-520

Fischer PH, Brunekreef B, Lebret E (2004) Air Pollution Related Deaths during the 2003 Heat Wave in the Netherlands. Atmos Environ 38(8): 1083-1085

Frich P, Alexander LV, Della-Marta P, Gleason B, Haylock M, Klein Tank AMG, Peterson T (2002) Observed Coherent Changes in Climatic Extremes during the Second Half of the Twentieth Century. Climate Res 19:193-212

Hansen A, Bi P, Nitschke M, Ryan P, Pisaniello D, Tucker G (2008) The Effect of Heat Waves on Mental Health in a Temperate Australian City. Environ Health Perspect 116(10):1369-1375

Hersbach H, Bell B, Berrisford P, Hirahara S, Horányi A, MuñozSabater J, Nicolas J, Peubey C, Radu R, Schepers D, Simmons A, Soci C, Abdalla S, Abellan X, Balsamo G, Bechtold P, Biavati G, Bidlot J, Bonavita M, De Chiara G, Dahlgren P, Dee D, Diamantakis M, Dragani R, Flemming J, Forbes R, Fuentes M, Geer A, Haimberger L, Healy S, Hogan RJ, Hólm E, Janisková M, Keeley S, Laloyaux P, Lopez P, Lupu C, Radnoti G, de Rosnay P, Rozum I, Vamborg F, Villaume S, Thépaut JN (2020) The ERA5 Global Reanalysis. Q J R Meteorol Soc 146(730):1999-2049

Hu K, Guo Y, Hochrainer-Stigler S, Liu W, See L, Yang X, Zhong J, Fei F, Chen F, Zhang Y, Zhao Qi, Chen G, Chen Q, Zhang Y, Tingting Ye Lu, Ma SL, Qi J (2019) Evidence for Urban-Rural Disparity in Temperature-Mortality Relationships in Zhejiang Province, China. Environ Health Perspect 127(3):1-11

Kent ST, McClure LA, Zaitchik BF, Smith TT, Gohlke JM (2014) Heat Waves and Health Outcomes in Alabama (USA): The Importance of Heat Wave Definition. Environ Health Perspect 122(2):151-158

Knowlton K, Kulkarni SP, Azhar GS, Mavalankar D, Jaiswal A, Connolly M, Nori-Sarma A, Rajiva A, Dutta P, Deol B, Sanchez L, Khosla R, Webster PJ, Toma VE, Sheffield P, Hess JJ (2014) Development and Implementation of South Asia's First HeatHealth Action Plan in Ahmedabad (Gujarat, India). Int J Environ Res Public Health 11(4):3473-3492

Kosaka Yu, Xie SP (2013) Recent Global-Warming Hiatus Tied to Equatorial Pacific Surface Cooling. Nature 501(7467):403-407

Kotharkar R and Ghosh A (2021) "Review of heat wave studies and related urban policies in South Asia." Urban Climate 36: 100777.

Lau, Steven Yuk Fai, Enfu Chen, N. Mohammad Kirran, Jian Cai, Maggie Haitian Wang, Benny Chung Ying Zee, Shi Zhao, Ka Chun Chong, and Xiaoxiao Wang (2021) "Ambient Temperature and Relative Humidity as Possible Drivers of the Hand, Foot, and Mouth Disease Epidemics in Zhejiang Province, China.” Atmos Environ 244(September 2020): 117984.

Lin YK, Chang CK, Wang YC, Ho TJ (2013) Acute and Prolonged Adverse Effects of Temperature on Mortality from Cardiovascular Diseases. PLoS ONE 8(12):6-13

Liu W, Han Y, Li J, Tian X, Liu Y (2018) Factors Affecting Relative Humidity and Its Relationship with the Long-Term Variation of Fog-Haze Events in the Yangtze River Delta. Atmos Environ 193(September):242-250

Luan G, Yin P, Wang L, Zhou M (2019) Association between Ambient Temperature and Chronic Obstructive Pulmonary Disease: A Population-Based Study of the Years of Life Lost. Int J Environ Health Res 29(3):246-254

Lyon B (2009) Southern Africa Summer Drought and Heat Waves: Observations and Coupled Model Behavior. J Clim 22(22):6033-6046

Martínez-Garcia A, Rosell-Melé A, McClymont EL, Gersonde R, Haug GH (2010) Subpolar Link to the Emergence of the Modern Equatorial Pacific Cold Tongue. Science 328(5985):1550-1553

Montero JC, Miron IJ, Criado JJ, Linares C, Díaz J (2013) Difficulties of Defining the Term, Heat Wave, in Public Health. Int J Environ Health Res 23(5):377-379 
Moum JN, Perlin A, Nash JD, McPhaden MJ (2013) Seasonal Sea Surface Cooling in the Equatorial Pacific Cold Tongue Controlled by Ocean Mixing. Nature 500(7460):64-67

Mozumder MSI, Amin MSA, Uddin MR, Talukder MJ (2021) Coronavirus COVID-19 Outbreak and Control: Effect of Temperature, Relative Humidity, and Lockdown Implementation. Arch Pediatr 28(2):111-116

Mukherjee S, Mishra V (2018) A sixfold rise in concurrent day and night-time heatwaves in India under $2{ }^{\circ} \mathrm{C}$ warming. Scientific Report 8:16922. https://doi.org/10.1038/s41598-018-35348-w

Nissan H, Burkart K, Coughlan E, de Perez M, Aalst V, Mason S (2017) Defining and Predicting Heat Waves in Bangladesh. J Appl Meteorol Climatol 56(10):2653-2670

Nitschke M, Tucker GR, Hansen AL, Williams S, Zhang Y, Bi P (2011) Impact of Two Recent Extreme Heat Episodes on Morbidity and Mortality in Adelaide, South Australia: A Case-Series Analysis. Environ Health: A Glob Access Sci Source 10(1):1-9

NOAA. 2013. "State of the Climate: Global Climate Report for Annual 2013." NOAA National Centers for Environmental Information.

NOAA (2016) "State of the Climate: Global Climate Report for Annual 2015." NOAA National Centers for Environmental Information.

Oliva M, Navarro F, Hrbáček F, Hernández A, Nývlt D, Pereira P, Ruiz-Fernández J, Trigo R (2017) Recent Regional Climate Cooling on the Antarctic Peninsula and Associated Impacts on the Cryosphere. Sci Total Environ 580:210-223

Panda, S. K., Mi-Jin Hong, S. K. Dash, Jai-Ho Oh, and K. C. Pattnayak. 2020. "Relative Roles of Eurasian Snow Depth and Sea Surface Temperature in Indian and Korean Summer Monsoons Based on GME Model Simulations." Earth and Space Science.

Pascal M, Wagner V, Alari A, Corso M, and Tertre AL (2021) "Extreme heat and acute air pollution episodes: A need for joint public health warnings?"Atmos Environ 249:118249.

Pattnayak KC, Kar SC, Dalal M, Pattnayak RK (2017) Projections of Annual Rainfall and Surface Temperature from CMIP5 Models over the BIMSTEC Countries. Global Planet Change 152:152-166

Pattnayak KC, Abdel-Lathif AY, Rathakrishnan KV, Singh M, Dash R, Maharana P (2019) Changing Climate Over Chad: Is the Rainfall Over the Major Cities Recovering? Earth Space Sci 6(7):1149-1160

Pattnayak, KC, SK Dash, and SK Panda. 2016. Indian Summer Monsoon Circulation in the Warming Atmosphere. LAP LAMBERT Academic Publishing.

Perkins SE, Alexander LV (2013) On the Measurement of Heat Waves. J Clim 26(13):4500-4517

Pijls BG, Jolani S, Atherley A, Derckx RT, Dijkstra JIR, Franssen GHL, Hendriks S, Richters A, Venemans-Jellema A, Zalpuri S, Zeegers MP (2021) Demographic risk factors for COVID-19 infection, severity, ICU admission and death: a meta-analysis of 59 studies. BMJ Open 11:1-10

Reilly SBO, Daanen H, Deering K, Gerrett N, Huynen M.MTE, Lee J, Karrasch S, Wiesler FM, Mertes H, Schoierer J, Guillemot JS, Hazel PVN, Loenhout JA FV and Nowak D (2021) "COVID-19 and heat waves: New challenges for healthcare systems." Environ Res 198:111153

Rey G, Jougla E, Fouillet A, Pavillon G, Bessemoulin P, Frayssinet P, Clavel J, Hémon D (2007) The Impact of Major Heat Waves on All-Cause and Cause-Specific Mortality in France from 1971 to 2003. Int Arch Occup Environ Health 80(7):615-626

Robinson PJ (2001) On the Definition of a Heat Wave. J Appl Meteorol 40(4):762-775

Rohini P, Rajeevan M, Srivastava AK (2016) On the Variability and Increasing Trends of Heat Waves over India. Sci Rep 6:1-9

Russo S, Sillmann J, Sterl A (2017) Humid Heat Waves at Different Warming Levels. Sci Rep 7(1):1-7
Sahu, Saroj Kumar, Poonam Mangaraj, Gufran Beig, Anuja Samal, Chinmay Pradhan, Swetaleena Dash, and Bhishma Tyagi (2021) "Quantifying the High Resolution Seasonal Emission of Air Pollutants from Crop Residue Burning in India." Environ Pollut 286:117165

Sancho LG, Pintado A, Navarro F, Ramos M, Pablo MAD, Blanquer JM, Raggio J, Valladares F, Green TGA (2017) Recent Warming and Cooling in the Antarctic Peninsula Region Has Rapid and Large Effects on Lichen Vegetation. Sci Rep 7(1):1-8

Sharma D, Babel MS (2014) Trends in Extreme Rainfall and Temperature Indices in the Western Thailand. Int J Climatol 34(7):2393-2407

Shartova N, Shaposhnikov D, Konstantinov P, Revich B (2018) Cardiovascular Mortality During Heat Waves in Temperate Climate: An Association With Bioclimatic Indices. Int J Environ Health Res 28(5):522-534

Singh, V., and Vishal Mishra, V., 2021.Environmental impacts of coronavirus disease 2019 (COVID-19).Bioresource Technology Reports, 15: 100744.

Smith TT, Zaitchik BF, Gohlke JM (2013) Heat Waves in the United States: Definitions, Patterns and Trends. Clim Change 118(3-4):811-825

Steadman RG (1979) The Assessment of Sultriness. Part I. A Temperature-Humidity Index Based on Human Physiology and Clothing Science. J Appl Meteorol 18(7):861-873

Sung TI, Pei Chih Wu, Lung SC, Lin CY, Chen MJ, Huey Jen Su (2013) Relationship between Heat Index and Mortality of 6 Major Cities in Taiwan. Sci Total Environ 442:275-281

Talbot, Nick, Akika Takada, Andrew H. Bingham, Dan Elder, Samantha Lay Yee, and Nancy E. Golubiewski. 2021. "An Investigation of the Impacts of a Successful COVID-19 Response and Meteorology on Air Quality in New Zealand." Atmospheric Environment 254(2):118322.

Tiwari PR, Kar SC, Mohanty UC, Dey S, Sinha P, Raju PVS, Shekhar MS (2016) On the Dynamical Downscaling and Bias Correction of Seasonal-Scale Winter Precipitation Predictions over North India. Q J R Meteorol Soc 142(699):2398-2410

Tong S, Wang XY, Barnett AG (2010) Assessment of Heat-Related Health Impacts in Brisbane, Australia: Comparison of Different Heatwave Definitions. PLoS ONE 5(8):1-5

Tosepu, R., Gunawan, J., Efendy, D. S., Ahmad, L. O. A. I., Lestari, H., Bahar, H., et al. 2020. "Correlation between weather and Covid19 pandemic in Jakarta Indonesia." Science Total Environment, 725,138436 .

Trájer AJ, Nagy G, Domokos E (2019) Exploration of the Heterogeneous Effect of Climate Change on Ozone Concentration in an Urban Environment. Int J Environ Health Res 29(3):276-289

Wang J and Yan Z (2021) "Rapid rises in the magnitude and risk of extreme regional heat wave events in China." Weather Clim Extremes 34:100379

Zhang W, Li J, Zhao X (2010) Sea Surface Temperature Cooling Mode in the Pacific Cold Tongue. J Geophys Res: Oceans 115(12):12042

Zhang Y, Feng R, Ran Wu, Zhong P, Tan X, Kai Wu, Ma Lu (2017) Global Climate Change: Impact of Heat Waves under Different Definitions on Daily Mortality in Wuhan, China. Global Health Res Policy 2(1):1-9

Publisher's note Springer Nature remains neutral with regard to jurisdictional claims in published maps and institutional affiliations. 